\title{
PENERAPAN SISTEM TERDISTRIBUSI PADA TOGETHER IN A SINGLE CONNECTION (TSC) BERBASIS WEB
}

\author{
Zuliana, Hero Wintolo, Bambang Sudibya \\ Jurusan Teknik Informatika \\ Sekolah Tinggi Teknologi Adisutjipto \\ informatika@stta.ac.id
}

\begin{abstract}
Distributed system is a computer networking technology which can be hardware or software. In hardware distributed system by a collection of computers that are heterogeneous, being in the software system is distributed in the form of software that connects two applications in the form of client and server side. TSC method is a method that already existed before, which can be used increase the ranking of a blog. Implementation distributed system for TSC using landing page as the intermediary. Landing page serves as a liaison between web applications or blogs are listed as a member to raise the ranking of a database on the application server side. When someone does click on landing page seoindonesia, will open a blog or other web members. Landing page so it can be used as a way to count the number of visitors to a blog or website, which in turn can increase the number of page visits and 1 with 1 click button seoindonesia for test in histats.com.
\end{abstract}

Keywords: Distributed system, TSC method, Landing Page.

\section{Latar Belakang}

Sistem terdistribusi merupakan teknologi jaringan komputer yang dapat berupa perangkat keras atau perangkat lunak. Perangkat lunak sistem terdistribusi berupa perangkat lunak yang menghubungkan dua aplikasi berupa sisi client dan sisi server. Perangkat lunak sisi client pada sistem terdistribusi digunakan untuk memberikan laporan kepada perangkat lunak sisi server untuk implementasi metode TSC. Pengembangan yang dilakukan terhadap penerapan metode ini dengan perancangan dan pembuatan aplikasi yang berbasis web serta menerapkan sistem terdistribusi. Penggunaan sistem terdistribusi ini dengan memanfaatkan landing page sebagai perantaranya. Dari latar belakang diatas dibuat tugas akhir dengan judul penerapan sistem terdistribusi pada Together in a Single Connection (TSC) dengan landing page berbasis web.

\section{Landasan Teori}

\section{Tinjauan Pustaka}

Devia Tito Setyaningsih (2012), Penerapan SEO (Search Engine Optimization) menggunakan teknik TSC (Together in a Single Connection) dalam meningkatkan kunjungan pada sebuah blog. Diperkenalkan dalam jurnal SEO yang diberi nama TSC (Together in a Single Connection). Pembukaan alamat web akan dilakukan secara berulang-ulang sampai halaman web mencapai 10 halaman web. 


\section{Sistem Terdistribusi}

Sistem distribusi adalah sebuah sistem yang komponennya berada pada jaringan komputer. Komponen tersebut saling berkomunikasi dan melakukan koordinasi hanya dengan pengiriman pesan (message passing). Kumpulan prosesornya saling berinteraksi melalui saluran komunikasi seperti LAN dan WAN menggunakan protokol standar seperti TCP/IP. Dalam pelaksanaannya sistem terdistribusi memiliki model sistem client - server merupakan bagian dari model sistem terdistribusi yang membagi jaringan berdasarkan pemberi dan penerima jasa layanan.

\section{Together in a Single Connection (TSC)}

TSC merupakan salah satu teknik dalam meningkatkan page view dan visitor sebuah blog. Teknik TSC memanfaatkan dua atau lebih komputer client yang merupakan sebuah perangkat yang menerima dan menampilkan serta menjalankan aplikasi, sedangkan komputer server adalah perangkat yang menyediakan dan bertindak sebagai pengelola aplikasi, data, dan keamanannya. Komputer server dan client terhubung dengan teknik pemrosesan parallel, yaitu dengan mengirim alamat blog dari komputer server ke komputer client setiap hari menggunakan sebuah koneksi (modem), sehingga akan mempunyai alamat IP yang berbedabeda setiap koneksi dihubungkan.

\section{Search Engine Optimazion (SEO)}

SEO merupakan sebuah proses yang digunakan untuk mengoptimalkan dan memaksimalkan halaman blog untuk pencarian dalam mesin pencari. Proses tersebut merupakan sebuah teknik pemasaran internet yang ditujukan untuk meningkatkan trafik kunjungan dalam sebuah konten jaringan dan meningkatkan kualitas trafik sendiri. Penerapan SEO ini menggunakan sebuah algoritma yang digunakan pada sebuah mesin pencari. Salah satunya adalah algoritma PageRank. Algoritma ini memperhitungkan jumlah link yang mengarah ke situs tertentu dan jumlah trafik yang dihitung dari halaman itu sendiri dengan halaman yang terdapat link tersebut berada.

\section{Uji Coba}

\section{Penjelasan Aplikasi}

Aplikasi seoindonesia dapat diakses pada alamat url http://seoindonesia.web.id, pada dua halaman yang berbeda. Halaman tersebut adalah halaman untuk admin dan user. Halaman admin mempunyai halaman login yang berbeda dengan user, halaman admin dipergunakan untuk mengadministrasi data user seperti ranking alexa dan melihat kunjungan yang disebabkan banner yang digunakan untuk landing page. Halaman user terdiri dari halaman pendaftaran untuk anggota, login untuk anggota, tambah web atau blog, script untuk dipasang pada masing-masing web atau blog anggota, petunjuk pemasangannya, dan halaman untuk melihat kunjungan pada blog milik anggota. 


\section{Menguji Metode TSC}

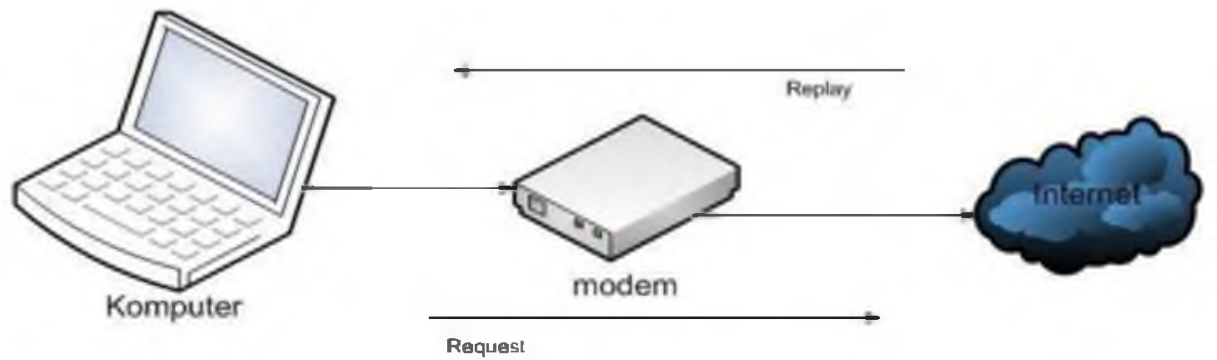

Gambar 1 Metode TSC

Pengujian metode TSC membutuhkan peralatan yaitu komputer dan modem. Modem digunakan untuk penghubung antara komputer dengan internet. Seperti terlihat pada Gambar 1 ketika modem sudah terkoneksi dengan internet, komputer dapat melakukan request, dan internet akan mereplay permintaan komputer. Penerapan TSC pada sistem terdistribusi terlihat saat server mengirimkan alamat web atau blog yang akan dibuka oleh komputer client yang memiliki banner seoindonesia, meski tidak seakurat pemrosesan parallel tetapi TSC cukup berhasil diterapkan di sistem terdistribusi.

\section{Analisa Sistem Terdistribusi}

Penerapan sistem terdistribusi pada sistem aplikasi seoindonesia memanfaatkan banner seoindonesia yang digunakan sebagai landing page untuk perantaranya. Banner seoindonesia seperti Gambar 2 berfungsi sebagai penghubung antara aplikasi web atau blog yang terdaftar sebagai anggota untuk menaikan ranking dengan database pada aplikasi sisi server. Kronologinya ketika user atau client melakukan klik terhadap banner seoindonesia, aplikasi sisi server mengirim data alamat blog atau website anggota seoindonesia untuk dibukakan pada tabs baru memberikan perintah browser membukakan halaman blog atau website yang terdaftar sebagai anggota dan sekaligus server seoindonesia mendapatkan beberapa informasi komputer client yang disimpan pada tabel log.

\section{seoindonesita}

Gambar 2 Banner seoindonesia

\section{Analisa Sistem}

Komputer mengakses sebuah alamat yang terdaftar sebagai anggota Seoindonesia. Daftar blog atau website anggota seoindonesia terlihat pada Tabel 1. 
Tabel 1 Daftar blog atau website

\begin{tabular}{|r|r|l|r|}
\hline id_website & id_user & \multicolumn{1}{|c|}{ Alamat } & Alexa \\
\hline 16 & 7 & reckys.wordpress.com & 5783954 \\
\hline 20 & 11 & jati.stta.ac.id & 1561091 \\
\hline 24 & 14 & fararainside.net & 3711316 \\
\hline 27 & 1 & candraadiputra.blogspot.com & 4441707 \\
\hline 33 & 19 & bundazaky.wordpress.com & 24387551 \\
\hline 37 & 7 & restografiti.blogspot.com & 22486813 \\
\hline 38 & 25 & herowintolo.stta.ac.id & 1561091 \\
\hline 39 & 25 & grosirhanduk.blogspot.com & 9452222 \\
\hline 41 & 25 & hero-wintolo.stta.ac.id & 1561091 \\
\hline 42 & 25 & compiler.stta.ac.id & 1561091 \\
\hline 44 & 27 & adjie01@wordpress.com & 26 \\
\hline 46 & 29 & ariska138.wordpress.com & 9161593 \\
\hline
\end{tabular}

Dari daftar blog atau website anggota seoindonesia seperti pada Tabel 1 tidak semua blog atau website yang terdaftar memasang script seoindonesia. Beberapa blog atau website yang tidak memasang script seoindonesia tercatat pada Tabel 2. Saat user membuka website atau blog yang terdaftar pada Tabel 2 sistem terdistribusi dipastikan tidak berjalan karena website atau blog tidak memasang banner seoindonesia.

Tabel 2 Website Tanpa Script

\begin{tabular}{|r|r|l|r|}
\hline id_website & id_user & \multicolumn{1}{|c|}{ Alamat } & Alexa \\
\hline 25 & 14 & aplikasionline.net & 0 \\
\hline 33 & 19 & bundazaky.wordpress.com & 24387551 \\
\hline 34 & 18 & informatikajogja.blogspot.com & 0 \\
\hline
\end{tabular}

Dari beberapa aksi klik menghasilkan terbukanya beberapa tabs baru dengan alamat blog atau web yang berbeda-beda, hal ini terjadi karena adanya sistem terdistribusi. Jadi ketika melakukan aksi klik pada banner seoindonesia yang digunakan untuk landing page secara otomatis meredirect ke server seoindonesia dan selanjutnya seoindonesia melakukan aksi eksekusi random untuk membukakan alamat pada tabs baru. Hasil pengujian tersebut tersimpan dalam database yang di administrasi oleh admin.

\section{Analisa Perangkingan Seoindonesia}

Perankingan versi SeoIndonesia dipergunakan admin untuk mempermudah monitoring berjalannya sistem terdistribusi pada banner seoindonesia. Perankingan versi SeoIndonesia di sini mengurutkan kunjungan yang diakibatkan dari sistem banner dengan metode descending dengan menggunakan order by dalam MySQL. Sorce code pengurutan website sebagai berikut:

1.\$query="SELECT COUNT( * ) AS jumlah, referral FROM log GROUP BY referal

2.order by jumlah desc";

3.\$pesan="Semua Waktu";

Dari potongan source code di atas didapatkan hasil seperti Tabel 3. 
Tabel 3 seo referal

\begin{tabular}{|r|l|r|}
\hline \multicolumn{1}{|c|}{ No } & \multicolumn{1}{|c|}{ Alamat } & $\begin{array}{c}\text { jumlah } \\
\text { referral }\end{array}$ \\
\hline 1 & http://candraadiputra.blogspot.com/ & 41 \\
\hline 2 & http://rizkitanjung.blogspot.com/ & 29 \\
\hline 3 & http://p00c4nb4w3l.blogspot.com/ & 25 \\
\hline 4 & http://ko-ko-ro-shop.blogspot.com/ & 20 \\
\hline 5 & http://grosirhanduk.blogspot.com/ & 19 \\
\hline 6 & http://jati.stta.ac.id/ & 18 \\
\hline 7 & http://www.fararainside.net/ & 18 \\
\hline & http://al-islam-indonesia.blogspot.com/2013/04/apakah- & 15 \\
\hline 8 & $\underline{\text { wahabi-sesat.html }}$ & 13 \\
\hline 9 & http://blue-evil.blogspot.com/ & 13 \\
\hline 10 & http://pianistkecil.wordpress.com/ & 13 \\
\hline 11 & http://www.herowintolo.stta.ac.id/ & 12 \\
\hline 12 & http://www.compiler.stta.ac.id/ & 11 \\
\hline 13 & http://ourjunior.wordpress.com/ & 10 \\
\hline 14 & http://www.hero-wintolo.stta.ac.id/ & \\
\hline
\end{tabular}

\section{Analisa Perankingan Histats}

Histats dalam sebuah blog menampilkan jumlah pengunjung yang online, jumlah pengunjung dalam sehari, jumlah pengunjung yang aktif membuka blog, menampilkan halaman populer di blog tersebut, dan informasi lainnya. Analisa perangkingan Histats diwakili pada sebuah website yang memasang Histats yaitu website dengan alamat http://herowintolo.stta.ac.id. Seperti pada Gambar 3 menunjukan situs web sebelum di uji coba. Berhasil atau tidaknya hasil dari uji coba ini dilihat dari visitor yang didapat setelah uji coba.

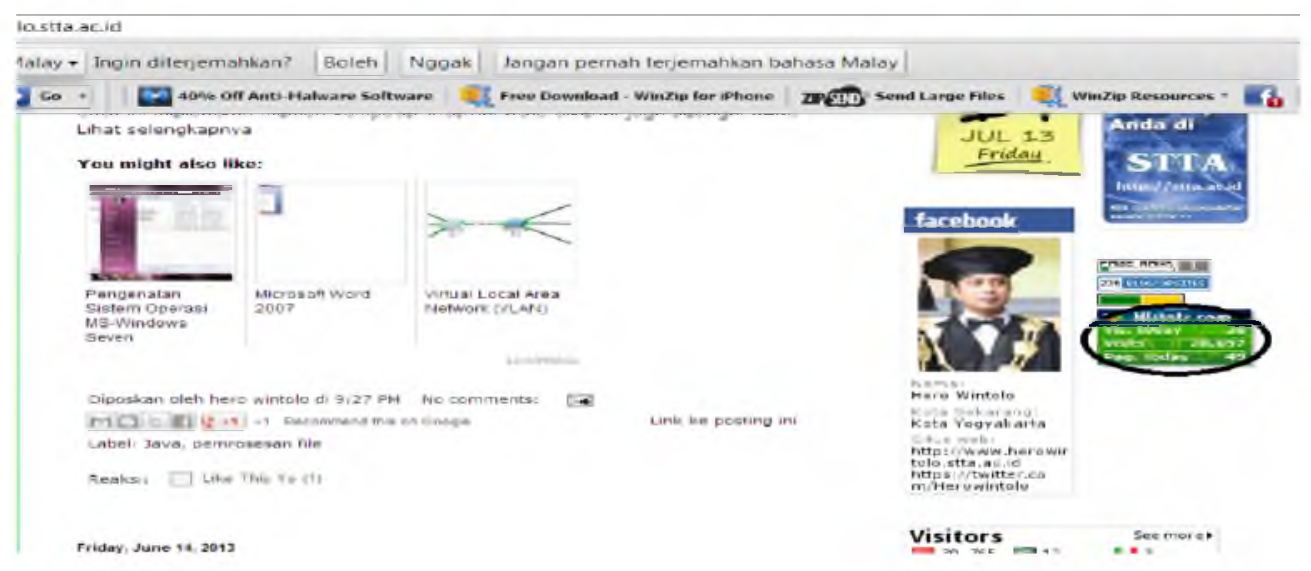

Gambar 3 Menunjukan analisa sebelum uji coba

Hasil uji coba program pada Gambar 4 menunjukan bahwa setelah dibuka dengan aksi klik banner 1 kali untuk visitor naik 1 dari 28.697 menjadi 28.698 dan visitor today atau kunjungan perhari naik 1 juga dari 36 menjadi 37. 


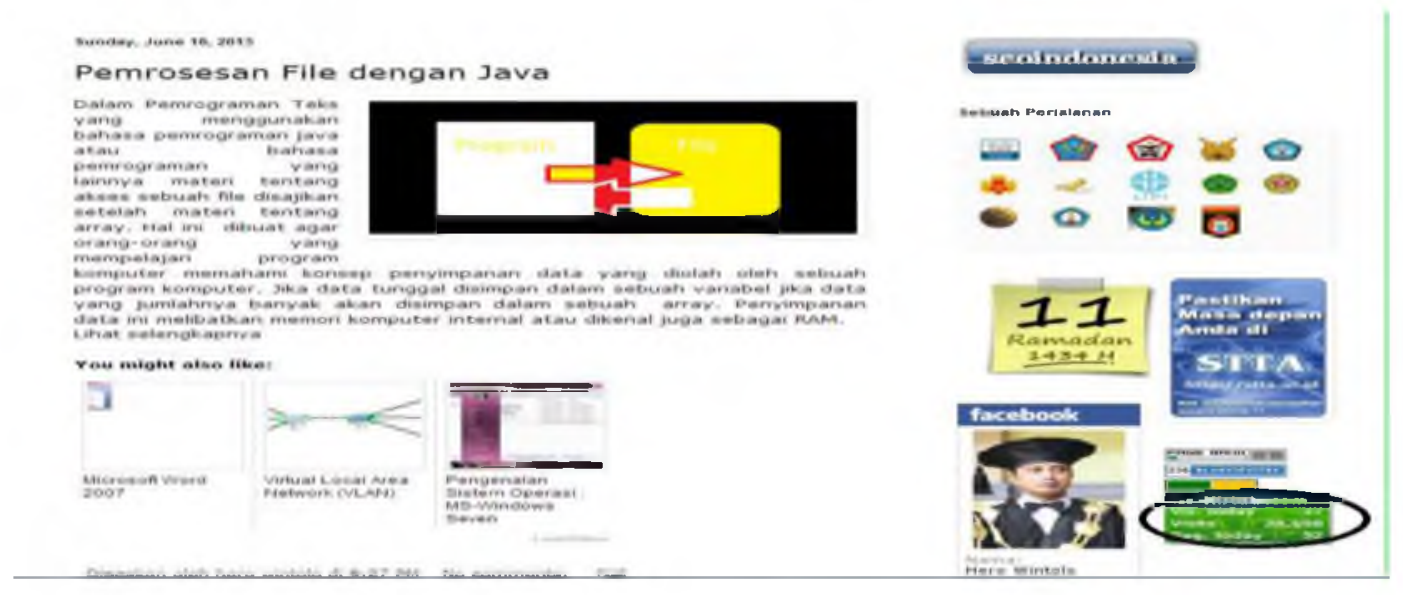

Gambar 4 Menunjukan hasil uji coba

\section{Analisa Perankingan Alexa}

Analisa perankingan pada alexa dimulai dari tanggal 10 Juli-19 Juli. Dengan waktu 9 hari terjadi perubahan seperti pada Tabel 4 . Menurunya ranking menjadi indikator bahwa semakin kecil ranking dalam alexa maka semakin dikenal website dan blog.

Tabel 4 Estimasi kenaikan rangking versi alexa

\begin{tabular}{|r|l|r|r|}
\hline No & \multicolumn{1}{|c|}{ Alamat } & Sebelum & Sesudah \\
\hline 14 & adiie01@wordpress.com & 26 & 25 \\
\hline 15 & jati.stta.ac.id & 1699627 & 1570117 \\
\hline 16 & herowintolo.stta.ac.id & 1699627 & 1570117 \\
\hline 17 & hero-wintolo.stta.ac.id & 1699627 & 1570117 \\
\hline 18 & compiler.stta.ac.id & 1699627 & 1570117 \\
\hline 19 & fararainside.net & 3398572 & 3736648 \\
\hline 20 & candraadiputra.blogspot.com & 3879757 & 4020977 \\
\hline 21 & reckys.wordpress.com & 5835733 & 5824486 \\
\hline 22 & ariska138.wordpress.com & 9161593 & 9231545 \\
\hline 23 & grosirhanduk.blogspot.com & 9519484 & 9523840 \\
\hline 24 & restografiti.blogspot.com & 22605281 & 22516423 \\
\hline 25 & bundazaky.wordpress.com & 24606702 & 24384017 \\
\hline
\end{tabular}

\section{Kesimpulan Dan Saran}

\section{Kesimpulan}

Dari hasil uji coba, dapat ditarik beberapa kesimpulan sebagai berikut :

1. Perangkat lunak yang berbasis web dapat digunakan untuk membangun sistem terdistribusi.

2. Metode TSC dapat digunakan dalam sistem terdistribusi untuk menaikkan ranking dengan kunjungan web atau blog dari web atau blog lainnya. Dari 1 klik button seoindonesia pada web atau blog mendapatkan ranking 1 kunjungan untuk web atau blog asal. 
3. Landing page dapat digunakan sebagai cara untuk menghitung jumlah pengunjung sebuah blog atau website yang pada akhirnya dapat menaikkan 1 kunjungan dan jumlah halaman dengan 1 klik button seoindonesia.

4. Berdasarkan survey dari pengguna seoindonesia sangat membantu dalam mempromosikan website atau blog secara gratis.

\section{Saran}

1. Sistem aplikasi seoindonesia supaya lebih dipromosikan dan dipublikasikan ke blogger agar anggotanya semakin banyak.

2. Blog atau web anggota dikatagorikan ke dalam masing-masing jenis agar user merasa nyaman dalam mendapatkan informasi

\section{Daftar Pustaka}

Helianthusonfri, Jefferly, 2012, Meledakan Profit dengan Blog dan Email. PT Elex Media Kumputindo, Jakarta.

Setyaningsih, D.T.,2012 Penerapan SEO (Search Engine Optimization) Menggunakan Teknik TSC (Together in a Single Connection) Dalam Meningkatkan Kunjungan Pada Sebuah Blog. Compiler Jurnal Adisutjipto Informartics Society: Volume I, No 2, November 2012. ISSN 2252-3839, Jurusan Teknik informatika Sekolah Tinggi Teknologi Adisutjipto, Yogyakarta.

Tanenbaum, Andrew S., Maarten van Steen, 2002, Distributed Sistem Principles and Paradigms. Prentice Hall. 
Zuliana, Hero Wintolo, Bambang Sudibya 